\title{
Emerging Trends in Materials and Manufacturing Engineering
}

\author{
Sivaprakash Katakam ${ }^{1} \cdot$ V. Muthupandi ${ }^{1}$
}

Received: 27 February 2017/ Accepted: 27 February 2017/Published online: 7 March 2017

(C) The Indian Institute of Metals - IIM 2017

With recent initiative by Government of India on 'Make In India', it is felt that a conference is essential to share the knowledge on the present advancements taking place across the globe in both materials and manufacturing engineering. Hence, the Department of Metallurgical and Materials Engineering, National Institute of Technology Tiruchirappalli, India has taken an initiative by conducting the International Conference on Emerging Trends in Materials and Manufacturing Engineering (IMME17) on the occasion of its Golden Jubilee Year, during 10-12 March, 2017. Though the conference is the first edition of the proposed biennial event, it has attracted more than 1200 abstracts. Out of them, only 400 were selected for full paper submission. From the submitted papers, through a peer review process by experts in the respective fields, only 320 papers were selected for presentation in the conference. This special issue of The Transactions of The Indian Institute of Metals (Trans. IIM) on "Emerging Trends in Materials and Manufacturing Engineering" consists of 40 technical papers selected from the total presented papers. Along with 6 Indian eminent persons, 10 experts from various parts of the globe have come forward to deliver Plenary and Key Note Lectures in the conference, on our request. The conference offered a platform to a large number of Indian and overseas scholars to present their findings and exchange the knowledge and also to hear the peers through the 3-day proceedings. We strongly believe that this special issue will be a source of information and will be a reference for both academicians and practicing engineers working in the areas of materials and manufacturing engineering. The papers of the special issue reflect the theme of the conference by covering topics: materials science, mechanical behavior of materials, materials joining, high temperature materials, materials processing, alloy design and modelling and simulation. We thank the authors for contributing their latest research and to the reviewers for sparing their valuable time for critically reviewing the manuscripts. Thanks are also due to the Prof. K. Bhanu Sankara Rao, Chief Editor, Tran. IIM, Dr. R. Sandhya, Managing Editor, Trans. IIM and to Springer for agreeing to publish the selected papers as a special issue of the Tran. IIM. We specially record our appreciation to the production team of Springer for their dedicated efforts in bring out this issue in time. We also thank everyone of IMME17 team, who have helped in successfully bringing out this special issue.
Sivaprakash Katakam

ksp@nitt.edu

1 National Institute of Technology, Tiruchirappalli, Tamil Nadu, India 